\title{
CARACAS A TRAVÉS DE SUS TERREMOTOS El impacto de los sismos en la evolución urbana de la ciudad, siglos XVII-XIX
}

\section{CARACAS THROUGH ITS EARTHQUAKES The impact of the seisms on the urban development of the city, XVIII-XIX centuries}

\author{
Alejandra Leal Guzmán \\ Fundación Venezolana de Investigaciones Sismológicas \\ e-mail: aleal@funvisis.gob.ve
}

v. 7, n. 10 jan/ago (2015)

ISSN.1982-0569
Florinda T. Amaya

Facultad de Arquitectura y Urbanismo, Universidad Central de

Venezuela

e-mail: ftaamaya@qmail.com

\section{Resumen}

Santiago de León de Caracas siempre ha sido una ciudad de riesgos. Fundada, en 1567, en un valle fértil, pero de topografía abrupta, sometido a la acción sismogénica del sistema de fallas de San Sebastián, Caracas ha padecido a lo largo de cinco siglos de historia más de 700 sismos sentidos y 5 terremotos destructores. A pesar de la importancia que estos eventos han tenido en la configuración de la ciudad, sus efectos específicos sobre su estructura y su evolución urbana, no han sido atendidos formalmente. En tal sentido, el objetivo de este trabajo consiste en analizar, a partir de diversas fuentes, cuál ha sido el impacto de los terremotos en la evolución urbana de Caracas, entre los siglos XVII y XIX

\section{Palabras clave}

Terremotos; evolución urbana; sismicidad histórica de Caracas

\begin{abstract}
Santiago de León de Caracas has always been a city of risks. Founded in 1567, in a fertile valley but steep topography, subjected to the action of seismogenic fault system San Sebastian, Caracas has suffered over five centuries of history over 700 earthquakes five senses and destructive earthquakes. Despite the importance of these events have had in shaping the city, its specific effects on urban structure and evolution, have not been formally served. In this regard the aim of this paper is to analyze, from various sources, what has been the impact of earthquakes on the urban evolution of Caracas, between the seventeenth and nineteenth centuries
\end{abstract}

\section{Keywords}

Earthquakes; urban development; historical seismicity of Caracas 


\section{Introducción}

La configuración de la ciudad constituye un proceso histórico que debe ser analizado, considerando todos aquellos factores de transformación que se han manifestado a lo largo de su evolución urbana (YUJNOVSKY, 1971, pp. 20-21); sin embargo, el análisis histórico de las configuraciones urbanas ha privilegiado los factores económicos, políticos, sociales, tecnológicos y culturales, soslayando el impacto transformador de las amenazas naturales existentes en el emplazamiento de las ciudades. Los terremotos, fenómenos que han acompañado dramáticamente la evolución de los núcleos urbanos asentados en zonas sísmicas, han sido estudiados considerando su impacto inmediato, pero no su influencia en el mediano y largo plazo.

En el caso de Venezuela, gracias al esfuerzo de investigadores provenientes de diversas disciplinas -incluyendo las ciencias sociales y las humanidades- se han dado los primeros pasos en la construcción de una historia social de los terremotos. Pese a todo, la historiografía venezolana, incluso aquellas obras dedicadas a la arquitectura y el urbanismo, ignora a plenitud el impacto de la sismicidad histórica del país sobre la evolución de las principales ciudades venezolanas. La única excepción la constituyen los míticos sismos del 26 de marzo de 1812, que sí han sido objeto de extensos estudios sociohistóricos (ALTEZ, 2006) y que recientemente han sido abordados en un conciso análisis que atiende factores geohistóricos y urbanos (CUNILL GRAÜ, 2012). En líneas generales, lo anterior significa que el potencial de los sismos como perturbadores y transformadores urbanos no ha sido lo suficientemente explorado. En este sentido, el propósito de este trabajo radica en visibilizar la sismicidad histórica de la ciudad de Caracas a través del análisis del impacto que han tenido en su evolución urbana, los terremotos de 1614, 1766, 1812 y 1900.

\section{Ciudades ordenadas, naturaleza desatada}

Según los intereses de la Corona española, la fundación de las ciudades y la organización territorial en el Nuevo Mundo, debía responder al mandato de ocupar, conquistar y defender. La relación de los españoles con la naturaleza de los nuevos territorios se pensaba en términos de recursos naturales explotables -especialmente metales preciosos, perlas, piedras preciosas-, no en función de potenciales amenazas a la existencia y al desarrollo de las ciudades (WOLF, 2000, pp. 169-170). El tema de

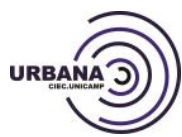


la vulnerabilidad sísmica en sus aspectos técnicos y culturales no fue considerado en la organización de las colonias españolas. Así vemos como en las Ordenanzas promulgadas por Felipe II en 1573 o el cuestionario geográfico de 1577, no se incorporaba la noción de riesgo natural, entendida como los daños potenciales que podían sufrir las ciudades, a causa de los terremotos y otros fenómenos naturales destructores (MUSSET, 2011, p. 69).

Efectivamente, cuando examinamos dicha legislación, a la luz de las amenazas y riesgos naturales presentes en América Latina, descubrimos que las Ordenanzas no ofrecían ninguna información, ninguna instrucción que permitiese a los colonizadores españoles enfrentarse a la naturaleza ignota y desatada del Nuevo Mundo. Una consideración importante respecto a las Ordenanzas de descubrimiento, nueva población y pacificación de las Indias, es que éstas no sólo constituían un marco legal para organizar la vida urbana sino que además conformaban un marco interpretativo para desentrañar las realidades americanas. Las Ordenanzas no eran simplemente un instrumento técnico sino también ideológico: la ciudad se pensaba a través de ellas. Sin embargo, este mismo examen reveló que el riesgo de epidemias y el peligro representado por los piratas sí estaban contenidos en las Ordenanzas de 1573. A diferencia de terremotos, tsunamis, volcanes y ciclones, las epidemias y los piratas constituían riesgos que ya estaban integrados en la experiencia social y cultural de los conquistadores y colonizadores.

\section{Los primeros tiempos de Caracas}

A mediados del siglo XVII, Caracas era una ciudad extremadamente vulnerable ante la ocurrencia de un terremoto. Por un lado, la penuria económica que marcó los primeros tiempos de la ciudad no alentaba la excelencia constructiva y, por el otro, los fundadores y constructores de Caracas no contaban con las herramientas técnicas ni simbólicas para enfrentarse a los retos planteados por la naturaleza americana. En cuanto a la evolución urbana de Caracas en su primer siglo de existencia, hay que considerar que la ciudad surgió prácticamente de la nada y que todo estaba por hacerse, era menester acondicionar el terreno y acarrear materiales de construcción, delimitar y asignar los solares y construir casas y templos, trazar calles y fabricar acequias para surtir de agua a los menesterosos habitantes (Imagen 1). 


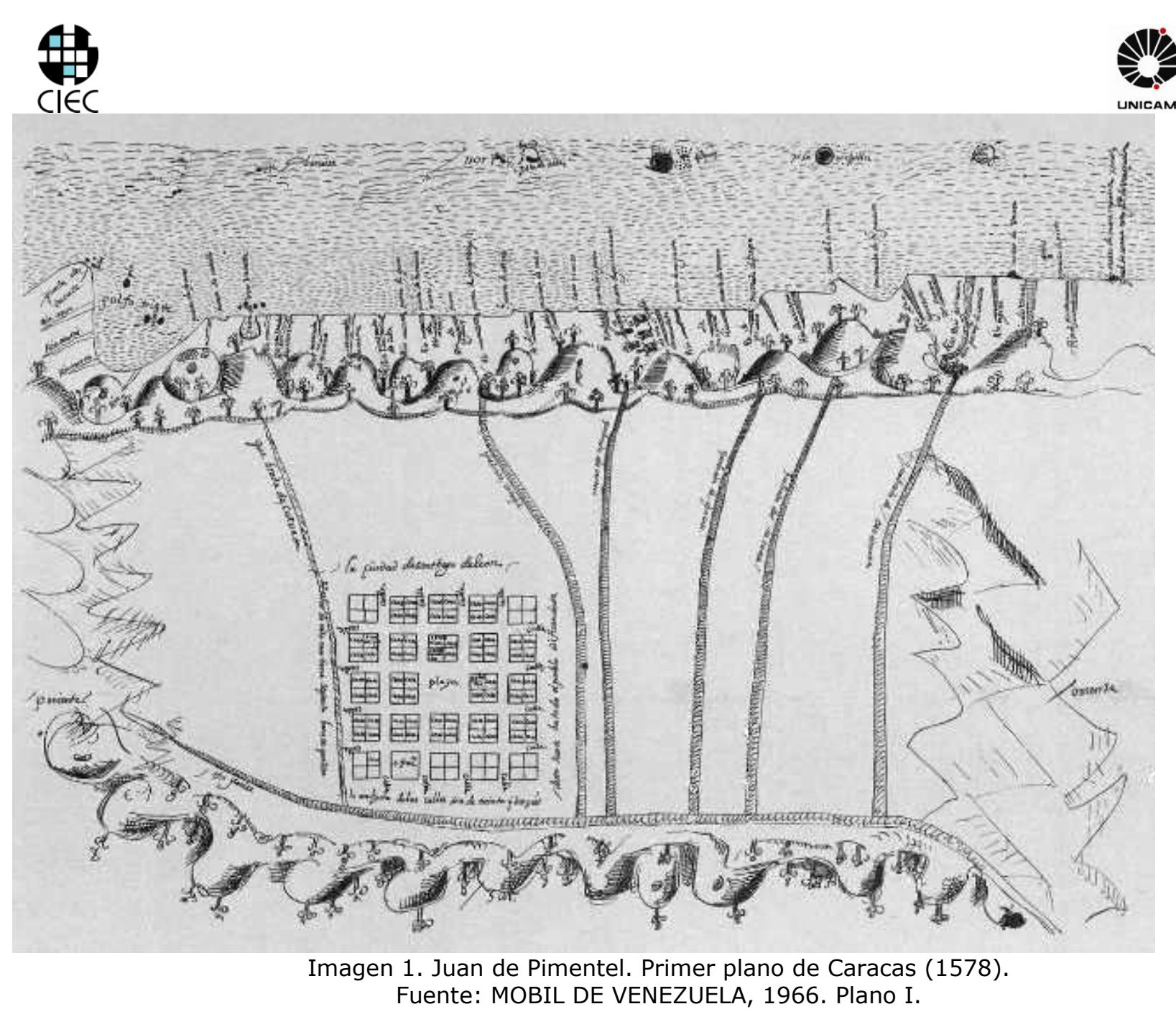

El primer plano de la ciudad, trazado por el gobernador Juan de Pimentel en 1578, once años luego de su fundación, nos muestra el área urbana inserta dentro del territorio geográfico y la importante conexión de la ciudad con el mar Caribe. También observamos los distintos cursos de agua que no solo sustentarían a la ciudad, sino que serían los mayores obstáculos a su expansión hasta mediado del siglo XVIII. La incipiente Caracas se revela vulnerable, sobrecogida por la naturaleza y sus ciclos, en medio de ese valle fértil, pero de topografía abrupta. El mismo plano nos informa que el proceso de asentamiento fue extremadamente arduo en aquel territorio virgen de toda traza urbana que además no producía oro ni otros metales y sostenía una agricultura embrionaria, más bien doméstica, que a duras penas alcanzaba a cubrir las necesidades de los pobladores españoles (ARCILA FARÍAS, 1961, p. 65).

Para complicar el panorama económico caraqueño, en 1594 se presentó una destructiva plaga de langostas $y$, al año siguiente, la ciudad fue saqueada e incendiada por el pirata inglés Amyas Preston. En medio de estas adversidades no resulta 
sorprendente que durante largos años, los edificios de la ciudad fueran simples estructuras de madera cubiertas de barro y paja, y su estructura urbana mantuviese el mismo esquema precario, como lo ilustran las descripciones hechas por Manuel Martínez de Manzanillo, en 1583 (ARELLANO MORENO, 1967). A lo largo del siglo XVI la ciudad crecerá lentamente consolidando los patrones e instituciones propias de la sociedad colonial.

\section{El primer terremoto de Caracas}

El terremoto de 1641, justamente conocido como el sismo de San Bernabé, por haber ocurrido en el día correspondiente del santoral católico, ocasionó grandes destrozos en Caracas y La Guaira, un saldo fatal que osciló entre 75 y 200 fallecidos y el consiguiente pánico. Una relación del año 1645 señalaba que a causa del terremoto Caracas quedó destruida a tal punto que "no quedó templo ni casa que no cayese, con que todos los vecinos han quedado tan aniquilados cuanto imposibilitados de reedificar sus viviendas en muchos años" (DORTA, 1967, p. 49). De estas palabras se desprenden no solo la magnitud de los destrozos ocasionados por el sismo de San Bernabé sino también que sus efectos socioeconómicos y urbanos se extendieron por largos años después de ocurrido aquél. Buena parte de la documentación referida al terremoto, producida entre 1641 y 1674 , es decir, un lapso de treinta y tres años, se refiere no tanto a los efectos del sismo como a las dificultades que atravesaron los caraqueños para reconstruir casas, templos y conventos.

Según el relato del obispo de Venezuela, fray Mauro de Tovar, el sismo ocasionó grandes destrozos en Caracas y en el puerto de La Guaira: todas las casas de piedra y de tapia cayeron o quedaron tan deterioradas que resultaba imposible habitarlas sin gran peligro para sus moradores ("El obispo Fr. Mauro de Tovar al Rey", Caracas, 14 de agosto de 1641, en AGN, Traslados, obispo fray Mauro de Tovar, Tomo I, f. 299). El sismo de San Bernabé, produjo daños graves en los edificios más importantes de la ciudad, arrasando con los hitos urbanos de Caracas. Todos aquellos edificios que representaban el poder de la Corona y de la Iglesia y que eran asiento de la educación y de la cultura colonial, resultaron destruidos o gravemente deteriorados, alterándose así el paisaje urbano de la ciudad que, según la descripciones de la época, se vio reducida a un conjunto de edificios ruinosos, escombros y frágiles casas de bahareque, al menos durante las tres décadas posteriores al sismo. Debido a la ruina producida por

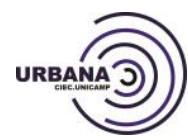

REVISTA ELETRONICA DO CENTRO INTERDISCIPLINAR DE ESTUDOS SOBRE A CIDADE . ISSN 1982-0569 v. 7, n. 10, jan /ago (2015). Dossiê História Urbana: a configuração de um campo conceitual 
el evento, el gobernador Ruy Fernández de Fuenmayor propuso mudar la asolada ciudad de Caracas para protegerla de futuros terremotos, repitiendo así un gesto que ya contaba con antecedentes en la América hispana. Debemos tener en cuenta que en muchas ocasiones el traslado de una ciudad representó "la única solución racional a problemas que se consideraban insolubles para la cultura y los medios técnicos de la época" (MUSSET, 2011, p. 35-36).

Sin embargo, la propuesta suscitó la inmediata y muy agresiva oposición del obispo Tovar, quien en una carta al rey aducía que mudar a Caracas a un nuevo emplazamiento no la protegería de futuros terremotos, toda vez que éstos eran causados por la ira de Dios, y aquélla era lo bastante larga para alcanzarlos donde quiera que fuesen. Por el contrario, mudar las costumbres impías de los caraqueños por otras piadosas, sí resultaría un remedio antisísmico eficaz, ya que los vecinos dejarían de merecer semejante castigo. Finalmente, la mudanza fue prohibida por real cédula de 15 de noviembre de 1642, y Caracas persistió largamente en su emplazamiento original. Al respecto, Gasparini y Posani afirman que "no deja de tener importancia la proposición de mudar la ciudad a otro sitio, porque además de ratificar la devastadora intensidad del sismo, deja entender que casi todo tuvo que rehacerse de nuevo" (GASPARINI y POSANI, 1998, p. 21).

Los destrozos provocados por el sismo de San Bernabé repercutieron significativamente en una Caracas que crecía muy lentamente y cuya población no superaba la cifra de 6.000 habitantes. La segunda mitad del siglo XVII estaría marcada por las consecuencias del sismo de 1641, por dificultades económicas, por epidemias y plagas diversas y por la amenaza de los piratas. Arellano Moreno califica estos años como uno de los momentos más difíciles en la vida de la ciudad (ARELLANO MORENO, 1967, p. 40). Entre los años de 1658 y 1687 la peste, una plaga de langostas y ratones, y epidemias de viruela y vómito negro azotan a Caracas que aún no lograba recuperarse del remezón sísmico. Una demostración de las dificultades del siglo es que no existe plano alguno que documente esta época infausta, circunstancia que revela tanto el escaso desarrollo urbano de Caracas como el modesto lugar que ocupaba dentro de la estructura colonial (GASPARINI y POSANI, 1998, p. 38).

Pese a todo, a finales del siglo XVII la ciudad emergía lentamente del marasmo: la estructura urbana caraqueña y su vialidad pasaron a ser regulares y proporcionadas. Los viajeros que visitaron la ciudad a lo largo del siglo XVIII describen elogiosamente

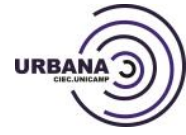

REVISTA ELETRONICA DO CENTRO INTERDISCIPLINAR DE ESTUDOS SOBRE A CIDADE . ISSN 1982-0569 v. 7, n. 10, jan /ago (2015). Dossiê História Urbana: a configuração de um campo conceitual 
sus calles anchas, largas, rectas y bien empedradas. Llama la atención que dos de estos viajeros, Oviedo y Baños en 1720 y Miguel de Santisteban en 1741, aluden a la naturaleza sísmica de Caracas, al señalar que las casas eran bajas debido al "recelo de los temblores" (ARELLANO MORENO, 1967, p. 41), temor sin duda ocasionado por la ingrata experiencia de 1641. Sobre este punto Alain Musset aduce que limitar la altura de las casas correspondía a "(...) las reglas tradicionales del urbanismo español en terrenos sísmicos" (MUSSET, 2011, p. 408). Si bien las penalidades de las centurias precedentes, como plagas y epidemias, continuaron perturbando la vida caraqueña a lo largo de todo el periodo colonial, durante el siglo XVIII las condiciones de la ciudad mejoraron considerablemente. El auge de la producción y exportación del cacao y el incremento de las actividades económicas actúan como catalizadores en la evolución urbana y demográfica de la ciudad.

En el año 1717 Caracas cuenta con 6.900 habitantes, número que aumenta a 14.000 entre los años 1744 y 1745 (BRITO FIGUEROA, 1961, p. 278). En 1772, don Juan Vicente Bolívar y Ponte, calcula entre 19.000 y 20.000 habitantes, cifras que coinciden con las señaladas por el obispo Martí. Joseph Louis de Cisneros registra 26.349 habitantes en 1764 , pero ese mismo año una nueva epidemia de viruelas merma notablemente a la población caraqueña, que en 1774 se componía de 18.669 habitantes. El plano del gobernador Joseph Carlos de Agüero, elaborado en 1775, representa la división de los barrios de la ciudad y, por lo tanto, el crecimiento urbano experimentado por Caracas a lo largo del siglo XVIII (Imagen 2). La identificación clara de estos sectores, significa un incremento demográfico notable que se expresa en la diversidad de actividades urbanas y en una creciente complejidad administrativa. Por otra parte, a diferencia del plano de Pimentel en el cual Caracas aparece enmarcada por los cursos de agua, aquí podemos apreciar cómo la ciudad se expande sobre las quebradas, quedando éstas incorporadas a la trama urbana. Caracas que desde su fundación había estado limitada en su expansión urbana por una abrupta topografía, comienza a superar las profundas simas que la constriñen gracias a la construcción de los puentes de La Trinidad (1775) y el de Carlos III (1777), que posibilitan la extensión de la trama urbana al Norte y al Este (ARCILA FARÍAS, 1961, pp. 75-78). 


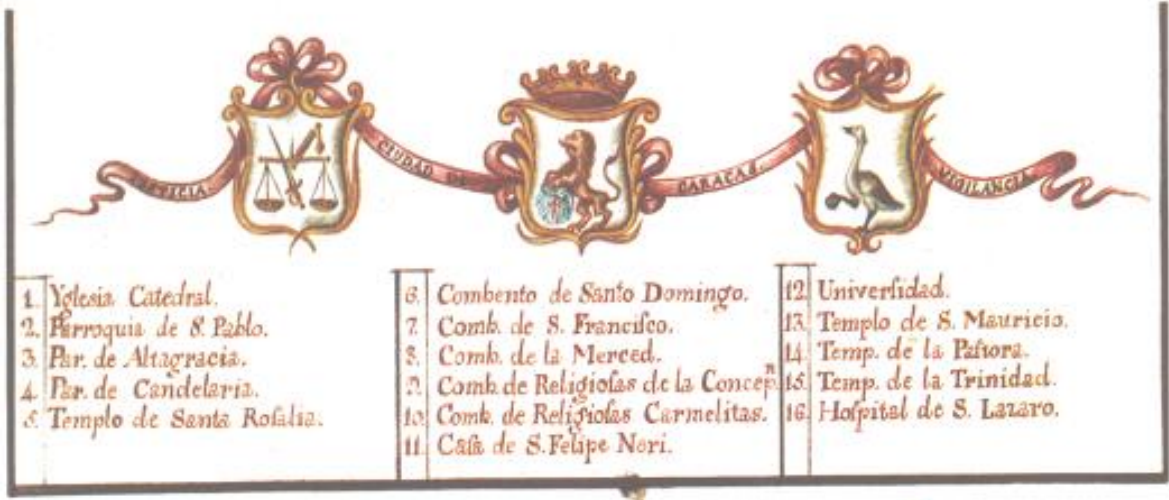

Plan de la Ciudad de Caracas, con divicion de sus Barrios. Fasos

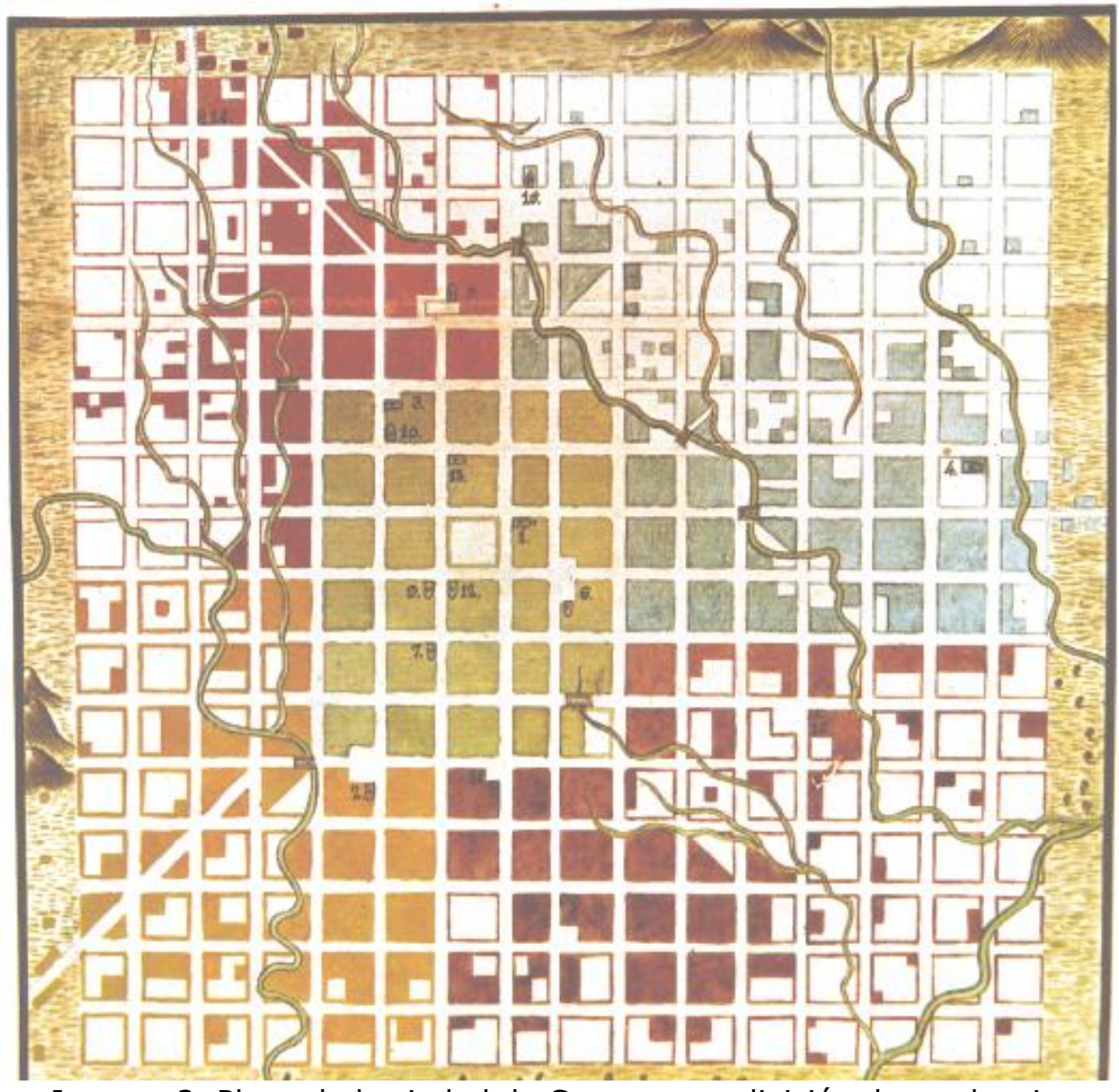

Imagen 2. Plano de la ciudad de Caracas con división de sus barrios. José Carlos Agüero, 1775.

Fuente: MOBIL DE VENEZUELA, 1966. Plano IV. 


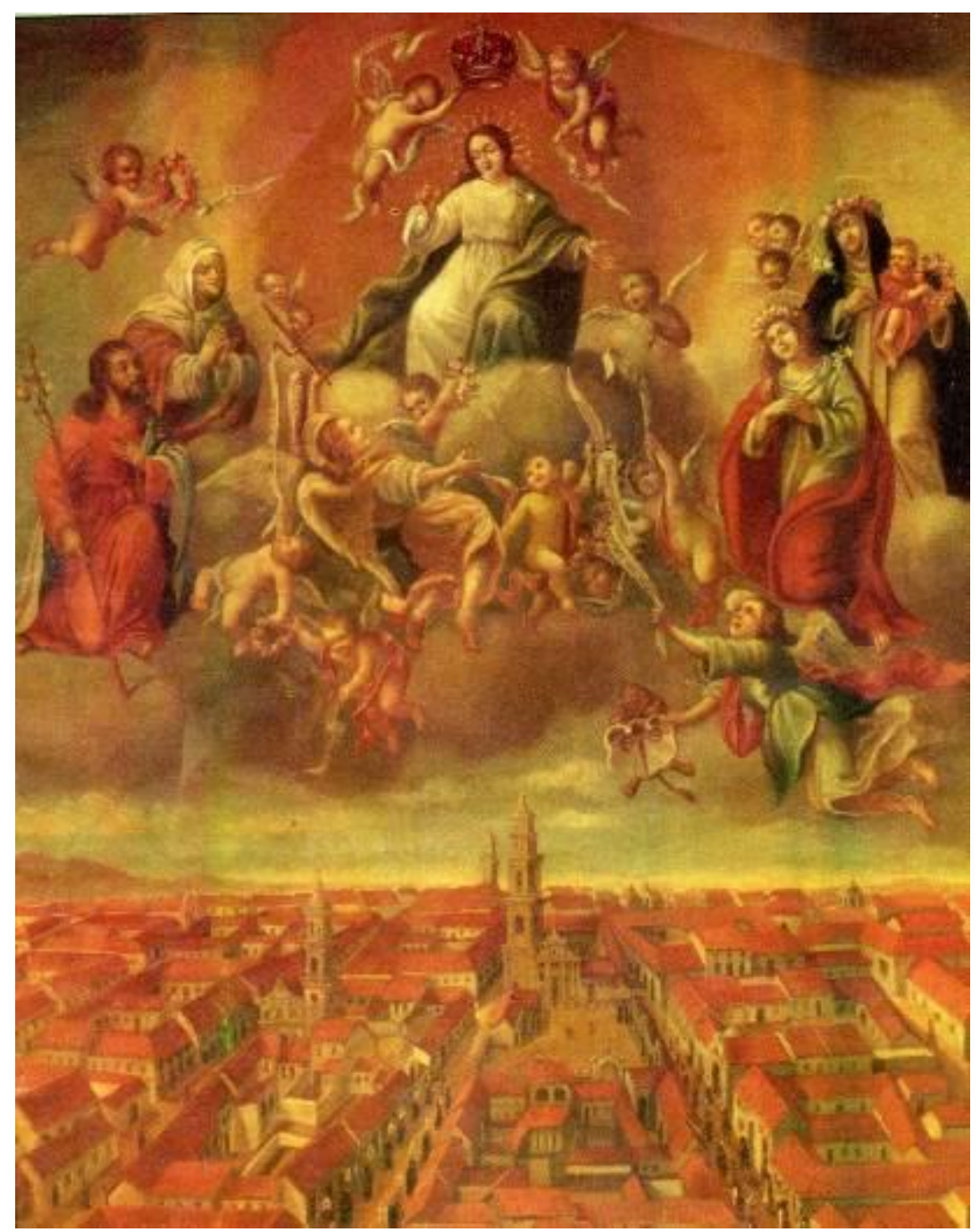

Imagen 3. Nuestra Señora de Caracas. Óleo sobre tela. Anónimo. Colección del Concejo Municipal de Caracas. Fuente: BRAVO, 2008, p. 46.

Otro signo del crecimiento urbano es la recomendación, hecha en 1773 por el gobernador Joseph Carlos de Agüero, de crear la figura de alcaldes de barrio para controlar mejor el comportamiento social de los caraqueños. En cuanto a los motivos para establecer esta figura, el gobernador Agüero señalaba "La extencion considerable de esta Ciudad, a causa del fomento de su populación, y de el estilo por temor de los terremotos de no fabricar las casas por comun que vajas, hace que la Poblasion posea un espasioso terreno, y que sus barrios se hallen considerablemente distantes de el centro de la Ciudad, en donde residen los jueses que administran justicia cuio celo no es vastante para velar como corresponde sobre la observancia de el Orden civil y economico, que hase la tranquilidad publica y pasifica sociedad mutua de los vecinos. 
Por este motivo en estos Barrios hallan comodo refugio los visios; los esclavos fugitivos y vagamundos acogida: mal cumplida la observansia de lo que se manda, y otros mas, perjudiciales males, que todos seran remediados, por el celo inmediato de estos comisionados" (AGÜERO, en DE SOLA RICARDO, 1967, p. 45).

Posteriormente, en 1775 y en 1778 , se promulgarían los documentos reguladores de sus funciones (SALAZAR, 2008). El ignoto viajero Joseph Louis de Cisneros que conoció Caracas en plena epidemia de viruelas de 1764 y a sólo dos años del sismo de Santa Úrsula, la retrata como una ciudad "bastantemente grande" y próspera (Imagen 3) (ARELLANO MORENO, 1967). El óleo anónimo Nuestra Señora de Caracas, nos ofrece una visión de la ciudad en el año 1766, justamente la fecha del terremoto de Santa Úrsula. Se trata de una panorámica de la Caracas de los techos rojos vista desde la colina del Calvario, en la cual se aprecia el trazado regular de las calles, tan celebrado por diferentes viajeros, y el modesto y monótono perfil urbano, en el cual destacan claramente el volumen de la Catedral y la altura de las torres de las iglesias. En primer plano se observan los cuatro cuerpos de la torre de la Catedral, que perdería uno de ellos a causa del sismo de 1812. También son visibles las arcadas que el gobernador Felipe Ricardos hiciese construir en torno a la Plaza Mayor, y que serían barridos por el impulso modernizador de Guzmán Blanco, a finales del siglo XIX (BRAVO, 2008, pp. 4647).

El periodo dieciochesco ha sido uno de los más brillantes de Caracas: para mediados de este siglo, los principales edificios de la ciudad estaban construidos, las calles habían sido nuevamente empedradas y las acequias estaban siendo refaccionadas (DUARTE, 1996, p. 34-35). La infraestructura y el equipamiento urbano se vieron enriquecidos con la construcción de puentes, jardines y alamedas como el de La Trinidad (1787). Así mismo se erigen importantes edificios como el Asilo de la Misericordia (1789); la Casa del Real Amparo (1792) y el Cuartel San Carlos (1792) (ZAWISZA, 1988 , p. 51). Las bellas artes y los oficios también atravesaron un tiempo de auténtico florecimiento.

\section{El terremoto de Santa Úrsula}

Poco más de un siglo transcurrió entre el pavoroso terremoto de San Bernabé y el sismo que sacudió buena parte del territorio venezolano el 21 de octubre de 1766, evento conocido como el sismo de Santa Úrsula, por haber ocurrido en el día

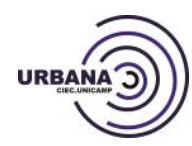

REVISTA ELETRONICA DO CENTRO INTERDISCIPLINAR DE ESTUDOS SOBRE A CIDADE . ISSN 1982-0569 v. 7, n. 10, jan /ago (2015). Dossiê História Urbana: a configuração de um campo conceitual 
correspondiente del santoral católico. En Caracas, el terrible remezón ocasionó graves desperfectos en templos y conventos. A pesar de la fuerza y la duración del temblor, las casas de los caraqueños, de paredes viejas y desplomadas, resistieron la sacudida sin acusar sus efectos, hecho que maravilló a los vecinos. Tampoco se registraron víctimas mortales ni heridos, ni aún casos leves ("Noticia del temblor de tierra padecido en la ciudad de Santiago de León de Caracas, Provincia de Venezuela en las Indias Occidentales, la madrugada del día 21 de octubre de 1766", Caracas, diciembre de 1766, en Archivo General de la Nación, Traslados, Audiencia de Caracas, f. 206). A diferencia de lo que ocurría en la Caracas abatida por el terremoto de 1641, hacia finales del siglo XVIII ya existían en la ciudad artesanos y profesionales de la construcción, capaces de realizar un peritaje de los daños sufridos por los templos y otros edificios afectados, y de acometer debidamente las labores de reparación o de reconstrucción. En tal sentido, podemos señalar que en ese momento, Caracas contaba con auténticos agentes urbanos, entendiendo el término como aquellas personas e instituciones que "directa o indirectamente y de forma decisiva, participan en la configuración de la ciudad" (ADUAR, 2000, p. 19).

Así pues, los conventos de Nuestra Señora de la Merced y de San Jacinto fueron reconocidos por el conde Miguel de Roncali, ingeniero de los Reales Ejércitos y comandante militar de la Plaza de La Guaira (GARCÍA CHUECOS, 1938, p. 249). Al mismo tiempo y a petición del gobernador don José Solano, se organizó una comisión para evaluar los daños en los edificios religiosos de Caracas: la Iglesia Catedral, el Convento de los Predicadores de San Jacinto, el de Nuestra Señora de la Merced, el de San Francisco, el de las Monjas Concepciones y el de las Carmelitas; y las iglesias de San Pablo, Altagracia, Candelaria, Santa Rosalía, San Lázaro, La Pastora y La Santísima Trinidad (GASPARINI y POSANI, 1998, p. 37).

Dicha comisión estaba conformada por el padre coadjutor del Colegio de los Jesuitas, el arquitecto alemán Miguel Schlessinger, por los maestros albañiles José Leonardo Mañer, Leandro Fuenmayor, Nicolás de Ponte y Juan Domingo del Sacramento y el maestro mayor de carpintería Santiago de Rojas. Habiendo realizado el peritaje requerido, informaron al gobernador Solano no haber encontrado daños graves o destrucción total sino daños moderados, es decir, que no comprometían la estabilidad y supervivencia de los edificios examinados. Los miembros de la comisión consideraron que estos destrozos podían ser reparados sin demasiada dificultad, siempre que se

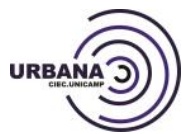
v. 7, n. 10, jan /ago (2015). Dossiê História Urbana: a configuração de um campo conceitual 
tuviese en cuenta la advertencia del padre Schlessinger de confiarle las reparaciones "(...) a maestro bien experimentado, para que se practiquen con las reglas y perfección que requieren" (GARCÍA CHUECOS, 1938, pp. 250-251). A diferencia de los sismos de 1641 y 1812, el evento de 1766 no produjo grandes daños en Caracas, ni tuvo un impacto significativo sobre su estructura y su evolución urbana.

Sin embargo, en la documentación correspondiente se evidencian pensamientos y acciones ante el sismo que no existieron en 1641. Por ejemplo, el nombramiento de una comisión para examinar los edificios deteriorados por el terremoto nos informa que las autoridades caraqueñas estaban conscientes de la necesidad de realizar un peritaje adecuado de los daños, pero también nos dice que disponían de los actores técnicos debidamente capacitados para esta labor. Igualmente, la previsión de encargar las reparaciones a personas competentes en el arte de la construcción, para asegurar la calidad de los trabajos, constituye un tema reiterativo en ocasión de los terremotos destructores, como puede observarse en los casos de los sismos de 1812 y de 1900.

\section{Del sismo de Santa Úrsula al terremoto del Jueves Santo}

El contexto cultural y económico de Caracas evolucionó substancialmente durante el siglo XVIII. El terremoto de 1766 no logró perturbar el desarrollo de la ciudad ni produjo ninguna alteración de naturaleza estructural en su sistema urbano. Más aún, hacia finales de este periodo, se experimentó una mejoría en lo que respecta a las calidades constructivas y también un crecimiento del equipamiento urbano. Tales circunstancias derivan de la actuación sostenida, en un lapso comprendido entre 1780 y 1811 , de los ingenieros españoles y de los diferentes maestros de las artes constructivas. La Guerra de Independencia y el terremoto de 1812, paralizarían casi por completo el ejercicio de estos profesionales, de modo que "Habrá que esperar los tiempos de Guzmán Blanco, o hasta finales del XIX, para tener un cuerpo profesional de esta calidad y dimensiones" (ZAWISZA, 1988, p. 51).

No hay evidencia histórica que señale, entre finales del XVIII y principios del XIX, cambios en las Ordenanzas urbanas o medidas de largo alcance frente a la amenaza sísmica que hayan sido inspirados por la ocurrencia del terremoto de Santa Úrsula. Desde 1753 existía la primera Ordenanza que regulaba el oficio de los alarifes, a saber, la Ordenanza particular para que sirva de regla del orden que se ha de tener, así los carpinteros como albañiles de esta ciudad en asunto del trabajo de su oficio así en sus

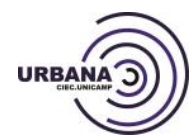

REVISTA ELETRONICA DO CENTRO INTERDISCIPLINAR DE ESTUDOS SOBRE A CIDADE . ISSN 1982-0569 v. 7, n. 10, jan /ago (2015). Dossiê História Urbana: a configuração de um campo conceitual 
hornales como en la distribución de sus clases. Dicho reglamento había sido sancionado por el gobernador y capitán general de Venezuela, don Felipe Ricardos. La historiadora Mariana Iribarren describe esta Ordenanza no como una guía para el ejercicio de las actividades correspondientes a los alarifes, sino más bien como un "rosario de cláusulas penales"; es decir, que la Ordenanza en cuestión no contenía precisiones técnicas referidas a la construcción, reparación y peritaje de edificaciones, sino que regulaba diversos temas como los rangos de los alarifes, los salarios, las herramientas requeridas, las horas laborables y establecía los castigos y multas impuestos en caso de ausencia o indolencia de los artesanos (IRIBARREN, 2010, p. 37).

Por el contrario, las instrucciones o régimen para el oficio de albañilería, redactadas en 1805 por el célebre alarife Juan Basilio Piñango, además de intentar regularizar las labores de estos artesanos, adscribiéndolos al ejercicio legal de su arte, sí profundizaban en temas referidos a la calidad de la técnica y de los materiales. Piñango comprendía que el crecimiento demográfico y urbano de Caracas debía ir acompañado de una infraestructura de calidad para que no resultase "mayor el daño público" ante cualquier contingencia futura que amenazase la estructura urbana (ZAWISZA, 1988, p. 54). Ciertamente no se hace mención alguna al riesgo sísmico, pero sí se expresa la conciencia respecto a que la producción de un desastre o de una emergencia empieza por la convergencia negativa de crecimiento demográfico y bajas calidades constructivas (GUIDOBONI y FERRARI, 2000, p. 688).

A principios del siglo XIX, la ciudad atravesaba un momento de florescencia urbana. Aunque no se trataba de una de las ciudades más espléndidas del Nuevo Mundo, Caracas produjo una grata impresión en los viajeros que la visitaron entre finales del siglo XVIII y principios del XIX. El conde Louis Phillipe de Ségur y sus acompañantes, quienes la conocieron hacia 1784, encontraron a la ciudad "grande, limpia, elegante, bien construida" (SÉGUR, en ARELLANO MORENO, 1967, p. 70). Juan María Romero, entusiasta visitante que arriba en 1801 calificó a Caracas como una ciudad hermosa y próspera. Otros viajeros famosos como Alejandro de Humboldt (1799-1801); Francisco Depons (1801-1804) y J. J. Dauxion Lavaysse (1805-1807) retrataron a Caracas como una ciudad limpia, regular, bien construida y de aspecto agradable, aunque quizás demasiado plácida. Depons admiró la "hermosa apariencia" de las casas particulares de la ciudad, construidas en tapia real y ladrillos. Humboldt,

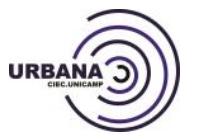

REVISTA ELETRONICA DO CENTRO INTERDISCIPLINAR DE ESTUDOS SOBRE A CIDADE . ISSN 1982-0569 v. 7, n. 10, jan /ago (2015). Dossiê História Urbana: a configuração de um campo conceitual 
sin embargo, opinó que estas viviendas eran "más elevadas de lo que deberían ser en un país sujeto a temblores de tierra" (ARELLANO MORENO, 1967).

La última relación de aquella Caracas aún no perturbada por el sismo de 1812, se la debemos al inglés Robert Semple, quien residió en la ciudad durante siete meses, entre 1810 y 1811 . En vísperas del terremoto, Semple se sorprende ante la hermosa perspectiva de Caracas que se ofrece a sus ojos cuando desciende hacia ella, desde el Ávila. El viajero inglés comenta elogiosamente la pulcritud de la ciudad y la regularidad de sus calles, bien pavimentadas. Por el contrario, sus plazas y edificios no suscitan en él impresiones notables (CUNILL GRAÜ, 2012).

Hacia la primera década del siglo XIX, el crecimiento de la ciudad se había consolidado gracias a las apreciables mejoras en cuanto a la infraestructura vial y equipamientos. Se habían construido varios hospitales como el Real Hospital de San Lázaro, Hospital de Caridad para Mujeres, Real Hospital de San Pablo, Hospital Militar y un Lazareto que se encontraba emplazado en las afueras de la ciudad (CUNILL GRAÜ, 2012, pp. 36-37). El río Catuche proveía el abastecimiento de agua potable, que era conducida a las fuentes públicas y a las casas particulares a través de tuberías de barro cocido. Este sistema, que resultó seriamente dañado por el sismo, continuaba deteriorado hacia 1822, pero unos veinte años más tarde, aproximadamente en 1844, ya estaba funcionando nuevamente. El abastecimiento de víveres era bastante fluido, abundante y variado, no sólo en el mercado de la Plaza Mayor, como lo reseñó Juan María Romero en 1801, sino también en "las numerosas bodegas y pulperías que se reparten en el centro y los barrios". Por el contrario, si de algo carecía Caracas en aquella época era de alumbrado público, ya que sólo se iluminaban los sitios urbanos importantes (ibídem, p. 37).

\section{Los terremotos de 1812}

Los sismos que sacudieron Venezuela el día 26 de marzo de 1812, arruinando en una tarde las ciudades de Barquisimeto, San Felipe, Caracas, La Guaira y Mérida, constituyen un hito de doble signo: histórico y sismológico. En primer lugar se le considera un hito histórico debido a sus repercusiones políticas y sociales que lo han convertido en el desastre nacional por excelencia. La historiografía venezolana ha presentado al evento de 1812 como la causa primordial de la pérdida de la Primera República, aunque el Libertador Simón Bolívar, testigo directo y de excepción, señalaba

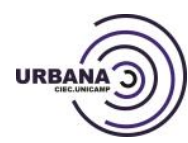

REVISTA ELETRONICA DO CENTRO INTERDISCIPLINAR DE ESTUDOS SOBRE A CIDADE . ISSN 1982-0569 v. 7, n. 10, jan /ago (2015). Dossiê História Urbana: a configuração de um campo conceitual 
que el sismo había sido un factor importante en el descalabro político, pero no el único (BOLÍVAR, 2013, pp. 43-45). Estos terremotos también son un hito sismológico, en tanto que han representado un enigma geológico durante los dos siglos que han transcurrido desde su impacto.

Para la mentalidad de principios del siglo XIX, lo ocurrido en 1812 fue un solo terremoto monstruoso que destruyó en breves instantes cinco ciudades importantes, y ésta ha sido la interpretación que ha persistido largamente en el imaginario venezolano y que además ha sido transmitida a través de la historiografía nacional y de los contenidos de la educación formal. Sin embargo, la sospecha que podía tratarse de más de un evento sísmico ha llevado a los investigadores a preguntarse qué ocurrió realmente la tarde del 26 de marzo de 1812, ¿cuántos eventos sísmicos sacudieron la Primera República ese lejano y trágico Jueves Santo? El ingeniero cumanés Melchor Centeno Graü -justamente considerado como un pionero de la sismología venezolanamanejaba la hipótesis de dos eventos diferentes (CENTENO GRAÜ, 1969, pp. 230-231). Por su parte, investigadores del Laboratorio de Geofísica de la Universidad de Los Andes, proponen tres focos sísmicos para 1812: el mayor evento entre Barquisimeto y San Felipe, un segundo evento frente a Caracas y un evento local cerca de Mérida (CHOY et al., 2010).

Investigadores de todo el mundo han documentado profusamente la manera como los contextos, política y económicamente inestables, amplifican los efectos de los fenómenos naturales destructores. En el caso que nos ocupa, el contexto venezolano se encontraba perturbado por las maniobras políticas y bélicas de la Guerra de Independencia, cuando irrumpe, sumamente destructor el sismo de 1812. El fenómeno fue descrito por el médico José Domingo Díaz, testigo directo:

Eran las cuatro, el cielo de Caracas estaba extremadamente claro y brillante, una calma inmensa aumentaba la fuerza de un calor insoportable, caían algunas gotas de agua sin verse la menor nube que las arrojase, y yo salí de mi casa para la santa iglesia Catedral. Como cien pasos antes de Ilegar a la plaza de San Jacinto, convento del [a] Orden de Predicadores, comenzó la tierra a moverse con un ruido espantoso; corrí hacia aquella, algunos balcones de la casa de correos cayeron a mis pies al entrar en ella, me situé fuera del alcance de las ruinas de los edificios y allí vi caer sobre sus fundamentos la mayor parte de aquel templo, y allí también, entre el polvo y la muerte, vi la 
destrucción de una ciudad que era el encanto de los naturales y de los extranjeros (DÍAZ, 2012, p. 31).

Todo el sector norte de Caracas sufrió "una verdadera retracción paisajística y de su poblamiento", que era visible 52 años después de ocurrido el sismo (CUNILL GRAÜ, 2012, p. 85). Las hileras de escombros al norte de Caracas constituían el paisaje que invariablemente dio la bienvenida a los viajeros durante décadas, como lo reseñaron en sus respectivas memorias diversos viajeros del siglo XIX (PINO ITURRIETA y CALZADILLA, 1993). Sir Robert Ken Porter, pintor, escritor y diplomático inglés, quien fue cónsul británico en Venezuela entre 1825 y 1840, retrató a la ciudad arruinada por el sismo de 1812 (Imagen 4).

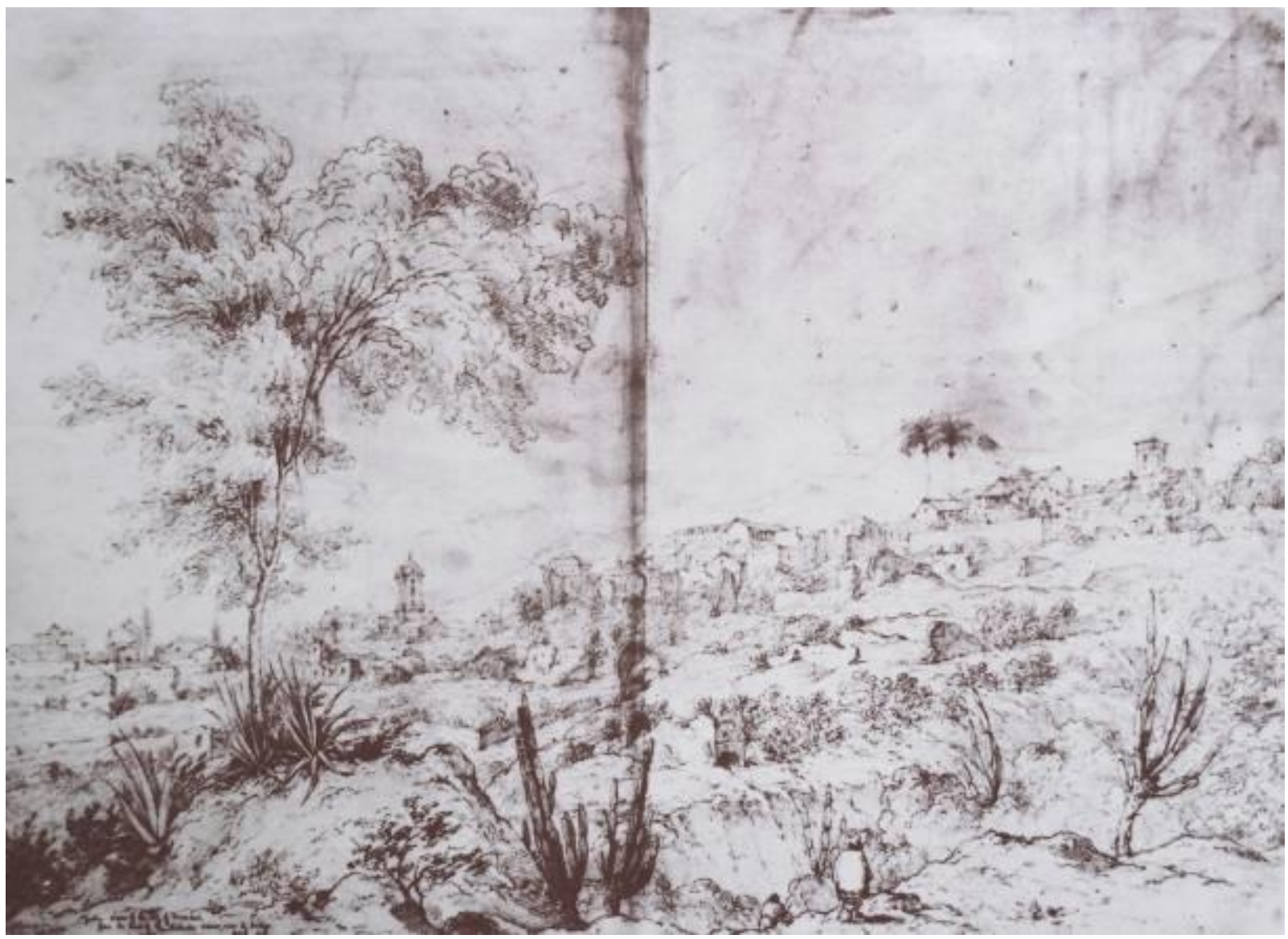

Imagen 4. El centro de Caracas visto desde el río Catuche. Sir Robert Ker Porter, 1826.

Fuente: GASPARINI y POSANI, 1998, p. 138.

El dibujo de Ker Porter documenta cómo, a catorce años de ocurrido el terremoto, las ruinas aún dominan el paisaje urbano. Al fondo, a la derecha, entre las tapias derruidas y la maleza, destaca la torre de la iglesia de Altagracia, y hacia la izquierda,

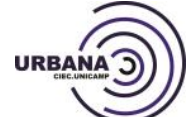

REVISTA ELETRONICA DO CENTRO INTERDISCIPLINAR DE ESTUDOS SOBRE A CIDADE . ISSN 1982-0569 v. 7, n. 10, jan /ago (2015). Dossiê História Urbana: a configuração de um campo conceitual 
a un nivel más bajo, se divisa la torre de la Catedral. Se aprecian unas pocas construcciones intactas y muchas viviendas deterioradas, sin paredes o destechadas: inhabitables. La impresión general es de abandono y desolación.

Cunill Graü, reflexiona sobre la distribución de daños en las viviendas según sus tipologías constructivas y señala que las humildes casas de bahareque con techos de paja o de palmas resistieron mejor que las viviendas de los artesanos y pequeños comerciantes, fabricadas en tapia con techos de paja y teja criolla. La destrucción también fue muy extendida entre las viviendas de las clases altas, construidas en tapia real, con fachadas de ladrillo y pesados techos de dos aguas cubiertos de tejas (CUNILL GRAÜ, 2012, pp. 55-56).

Por el contrario, mientras muchas casas de tapia sepultaron a sus ocupantes y sembraron las calles de escombros, las pocas casas de piedra que existían en Caracas resistieron tenazmente los efectos del terremoto y sus réplicas. Sin duda alguna, los terremotos de 1812 fueron los más destructores en toda la historia venezolana y también en la historia urbana de Caracas (ALTEZ, 2006). La infraestructura y el equipamiento de la ciudad resultaron severamente afectados por el sismo del 26 de marzo. Las calles quedaron interrumpidas por escombros y grietas; las aceras, muy deterioradas, tardaron años en ser reparadas. Aunque las fuentes públicas resistieron el sismo, el servicio de agua potable, que permitía llevar el líquido desde el río Catuche directamente a las casas de los vecinos, se resintió por la destrucción de las tuberías (CUNILL GRAÜ, 2012, p. 59).

Caracas quedó arruinada a tal punto que sus habitantes no se congregaron en las plazas, como sucedió, por ejemplo, tras el sismo de 1900, sino que, conminados por las autoridades, comenzaron a abandonar la ciudad, quedando solo unos pocos de centenares de vecinos en ella (DÍAZ, 2012, p. 33). Una parte de los caraqueños emigró a pueblos cercanos que habían sido menos afectados por el sismo, como La Victoria. Muchos hacendados marcharon a sus haciendas, en tanto que otro grupo se refugió extramuros, dando lugar a una "formación de hábitat espontáneo" en el sitio de Ñaraulí, que a finales de septiembre de ese mismo año contaba con 12.000 personas (CUNILL GRAÜ, 2012, p. 61).

\section{Reflexiones constructivas post 1812}

El geógrafo Pedro Cunill Graü, señala muy acertadamente que estos eventos transformaron radicalmente el paisaje urbano caraqueño: "Se destruyeron tres terceras

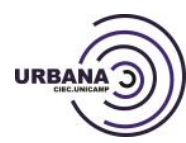

REVISTA ELETRONICA DO CENTRO INTERDISCIPLINAR DE ESTUDOS SOBRE A CIDADE . ISSN 1982-0569 v. 7, n. 10, jan /ago (2015). Dossiê História Urbana: a configuração de um campo conceitual 
partes de sus edificios, casi todas las iglesias (...) quedando cuarteadas y agrietadas las restantes viviendas. El trazado cuadricular de las calles se vio interrumpido por escombros y aberturas, lo mismo que los acueductos" (CUNILL GRAÜ, 2012, p. 50). Ante aquel panorama desolador se imponía la necesidad de rehabilitar y de reconstruir la ciudad, cuyas deficiencias edificatorias habían sido evidenciadas por el impacto de los sismos. El Cabildo de Caracas tomó las siguientes medidas: en primer lugar, comisionar a los alarifes Juan Basilio Piñango y Francisco Torres para realizar el reconocimiento de todas las construcciones afectadas por el sismo y presentar los informes consiguientes; ordenar que templos y parroquias se reconstruyesen en sus emplazamientos originales y prohibir la construcción de rancherías sobre las ruinas o fuera de los límites de la ciudad (IRIBARREN, 2010, p. 84-85).

Otro problema que debió enfrentar el Cabildo en aquellos días difíciles se refería a las reparaciones de mala calidad que se hacían en los edificios de Caracas. Los mismos propietarios se encargaban de retocar sus viviendas, ocultando los deterioros producidos por el sismo, en una práctica que difícilmente podía considerarse una reparación en toda regla y que debilitaba aún más aquellas construcciones. Por otra parte, los alarifes no se daban abasto, así que trabajaban de prisa y con grandes dificultades para procurarse materiales adecuados (ZAWISZA, 1998, p. 89).

Aunque la historiadora Mariana Iribarren afirma que los alarifes "no estaban en capacidad, ni era de su competencia hacer innovación para disminuir los problemas causados por sismos o para aminorar el agotamiento de los materiales empleados en las construcciones" (IRIBARREN, 2010, p. 62), el Alarife Mayor de Caracas, Juan Basilio Piñango, presentó ante las autoridades del Municipio los planos correspondientes a un proyecto de viviendas contra temblores, diseñadas según los materiales y las tecnologías disponibles en la época. Se tratada de unas construcciones "diseñadas con un sistema de horcones ('madera enterradas en tierra') arriostrados a nivel de arranque de techo y encima de los vanos de puertas y ventanas, verdadera estructura 'trabada' que ya respondía en cierta medida a los requerimientos antisísmicos" (ZAWSIZA, 1988, pp. 97-98).

Al examinar la propuesta de Piñango, a la luz de la filosofía de la sismorresistencia actual, se observa que el diseño de estas casas resuelve dos temas básicos: el peso de la vivienda sugiriendo una construcción liviana de madera y la estabilidad estructural

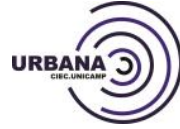

REVISTA ELETRONICA DO CENTRO INTERDISCIPLINAR DE ESTUDOS SOBRE A CIDADE . ISSN 1982-0569 v. 7, n. 10, jan /ago (2015). Dossiê História Urbana: a configuração de um campo conceitual 
de la misma, al procurar dotarla de solidez y buena conexión entre los elementos estructurales y no estructurales, a través de la horconadura y las riostras. Aunque en 1812 no existían códigos sismorresistentes según la definición actual de estos instrumentos, no se puede negar que la propuesta de Piñango evidencia la preocupación por adecuar las construcciones de la época a la naturaleza sísmica de la ciudad (LEAL GUZMÁN y MASTRANGIOLI, 2014, p. 573).

A lo largo de su ensayo "Arquitectura", publicado en 1842, el ingeniero Olegario Meneses da cuenta del estado de las artes constructivas en Caracas, esbozando prolijamente tópicos relacionados a la producción del riesgo sísmico en tanto que afectan la estabilidad y la resistencia de los edificios, a saber, la calidad de la técnica y de los materiales y la distribución de las edificaciones. Haciendo gala de una perspicacia notable frente al tema del riesgo sísmico, Meneses insistía en la necesidad de ejercer un efectivo control social sobre la excelencia de las edificaciones, promoviendo el estudio del arte de construir y exigiendo el cumplimiento de sus principios, temas que, medio siglo más tarde, se plantearían los ingenieros venezolanos a quienes tocó reflexionar sobre el sismo de 1900.

En este sentido, Meneses censuraba la insuficiencia de las Ordenanzas respectivas y de la supervisión ejercida por la policía urbana. Efectivamente, la revisión de las Ordenanzas y reglamentos de policía rural y urbana posteriores al sismo de 1812 nos llevó a concluir que estos instrumentos legales no contenían disposiciones lo bastantes precisas en lo que se refiere a la reducción del riesgo sísmico a través de la supervisión de las calidades constructivas. Por ejemplo, las Ordenanzas promulgadas sucesivamente entre los años 1824 y 1892 no reflejan en modo alguno la ocurrencia del sismo de 1812 y sus pavorosos efectos sobre la ciudad de Caracas, en el modo preciso en que sí lo hace el Reglamento de Policía para la reedificación del pueblo de La Guaira, el cual fue sancionado específicamente para enfrentar las consecuencias del sismo y prevenir, o mitigar, en la medida de lo posible, los efectos de otro temblor.

En general, las disposiciones que podrían considerarse más relevantes en cuanto al tema que nos ocupa y que están contenidas en las Ordenanzas de policía urbana y rural promulgadas entre 1824 y 1892, pueden resumirse en los siguientes puntos, los cuales se mantienen con pocas alteraciones en dichos reglamentos. En primer lugar, estas Ordenanzas establecen la obligación de denunciar, ante la policía urbana, la existencia de edificios "defectuosos" o ruinosos, pero sin definir con exactitud qué es 
un edificio defectuoso o ruinoso. Aquí puede apreciarse la referencia a las ruinas, tanto de los templos como de casas particulares, que campearon en Caracas durante largos años amenazando la vida de los transeúntes e incluso de las personas refugiadas en ellas, problemática expresada por Olegario Meneses en 1842 (MENESES, en ZAWISZA, 1988 , p. 95). En segundo lugar, se fijaban unas pocas reglas relacionadas a la actividad de los artesanos de la construcción que no iban más allá del requerimiento de obtener licencia para poder ejercer el oficio y de la obligación de hacerlo con eficacia y suficiencia, bajo el riesgo de recibir multas o sufrir el retiro de sus licencias.

Se trataba de disposiciones sumamente vagas y formuladas de manera muy general, lo que sin duda dejaba un amplio margen para su interpretación e incumplimiento. Estos documentos no ofrecen indicaciones puntuales respecto a la altura y estabilidad de los edificios, a la correcta aplicación de las técnicas constructivas o la calidad de los materiales utilizados. Los pocos artículos dedicados a la actividad de maestros mayores y alarifes no eran lo suficientemente precisos como para asegurar la calidad de la mano de obra que continuaba construyendo Caracas. Podríamos señalar que estas Ordenanzas no incorporaron las lecciones derivadas del terremoto de 1812.

\section{Caracas decimonónica}

Caracas entró al siglo XIX con una población que se sitúa aproximadamente entre los 40.000 y 42.000 habitantes, a pesar de lo cual su casco urbano permaneció más o menos invariable desde mediados del siglo XVIII. Alejandro de Humboldt estimó que para el año de 1812, la ciudad contaba con 50.000 personas. A los estragos del sismo, se suman las vicisitudes de la Guerra de Independencia y en consecuencia, la evolución urbana y arquitectónica de Caracas resulta seriamente perturbada, pues el crecimiento de la ciudad se redujo casi hasta detenerse. La ciudad tardó décadas en recuperarse de los destrozos y de los múltiples problemas económicos y políticos emanados de la guerra: las actividades constructivas y las obras públicas prácticamente se paralizaron (GASPARINI y POSANI, 1998, p. 135).

La Caracas de finales del siglo XIX, ya no era aquella ciudad colonial de los techos rojos sino una ciudad que había renovado al "estilo europeo" durante los últimos 30 años de dicho periodo. El paisaje urbano se transformó con la presencia de teatros, bulevares, monumentos, parques, comercios, tranvías. Una nueva vida urbana apareció 
en el escenario para satisfacer los anhelos burgueses de la nueva sociedad caraqueña.

El proyecto de modernidad urbana, más no de progreso industrial, gestado por el presidente Antonio Guzmán Blanco durante sus diferentes gobiernos desde 1870-1888, se centró en la construcción y renovación de edificios como la Asamblea Nacional, la Universidad y el Teatro Municipal que incorporaban los nuevos materiales y las técnicas constructivas importadas de Europa y Estados Unidos. La modernización urbana se plasmó con la construcción de nuevas calles, bulevares, puentes, tranvías, acueductos, cloacas, sistemas de alumbrado público. Se establecieron nuevas políticas higienistas, reglamentos que regulaban el orden urbano, las condiciones de funcionamiento y de sanidad de la ciudad.

El primer manifiesto de la concepción municipal de Guzmán fue la Ordenanza sobre Policía Urbana y Rural de 1871, en la que fueron controlados aspectos como el alineamiento de las manzanas centrales, se delimitaban las dimensiones de las nuevas calles en 50 "varas" de ancho; fueron prohibidos los techos de paja y los dueños de las casas que todavía los tenían fueron inducidos a sustituirlos por tejas. Para mejorar la ornamentación se modificaron rasgos característicos de la arquitectura colonial, tales como la sustitución de los vernáculos aleros por exóticas cornisas, que a la postre ocasionaron no pocos accidentes, al desprenderse de los edificios, durante el terremoto de 1900.

Las disposiciones guzmancistas alteraron el aspecto de las nuevas casas caraqueñas a tal punto que el colombiano Urdaneta encontró en ellas "poco o ningún vestigio de arquitectura española". Con miras a facilitar la administración de la ciudad que comenzaba a crecer, Guzmán dotó al Gobierno municipal de un mapa actualizado de toda Caracas, incluyendo las siete parroquias recién creadas. También intentó regularizar el tejido urbano hacia las afueras de la ciudad (ALMANDOZ, 2006, pp. 104105). Todas estas transformaciones y regulaciones permitieron mejorar las condiciones urbanas y de las edificaciones de la ciudad (Imagen 5). No obstante, el añorado sueño de Guzmán de convertir a Caracas en la pequeña París, no implicó cambios estructurales (CARABALLO PERICI, 1991, p. 59). 


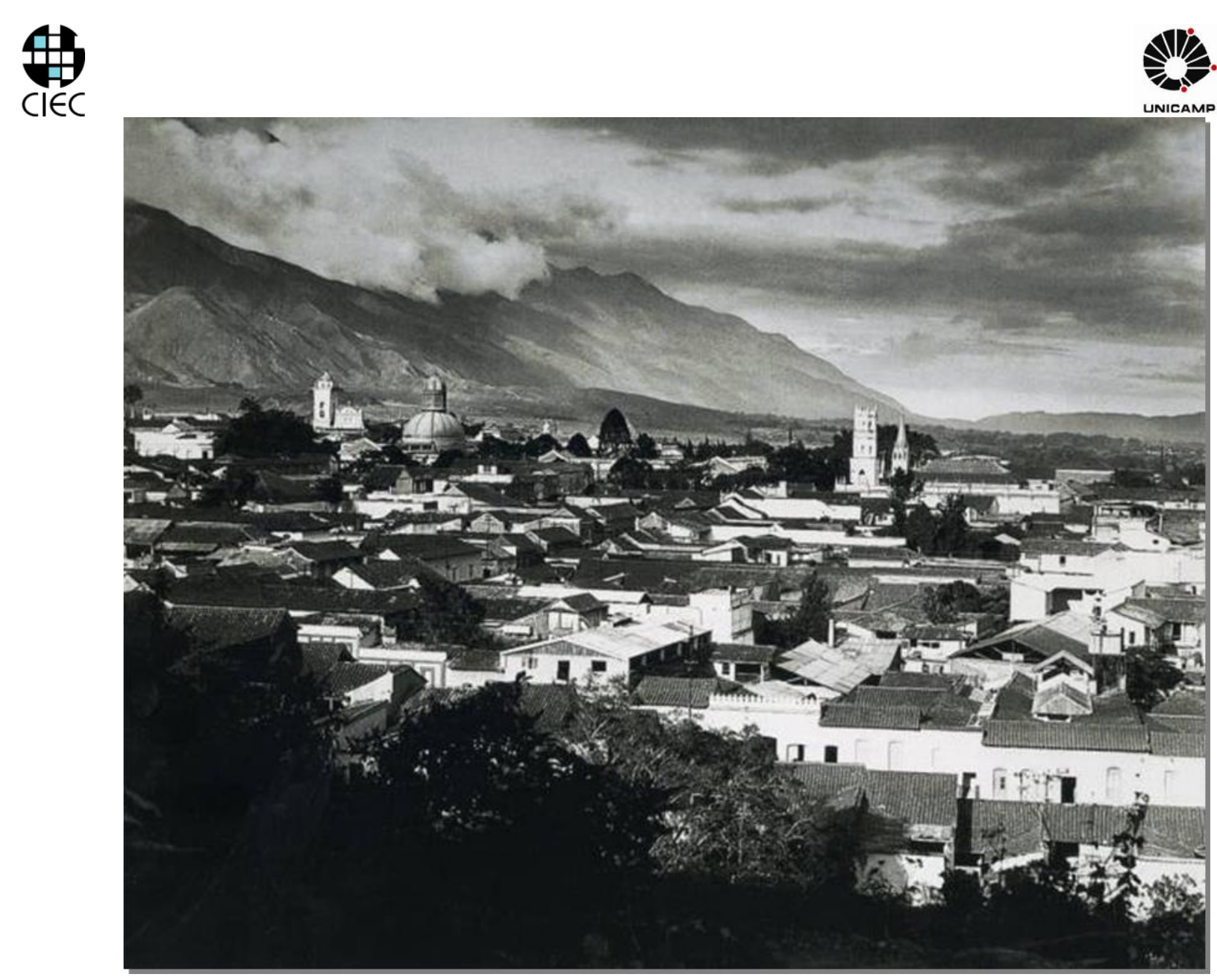

Imagen 5. Paisaje de Caracas, ca. 1900. Anónimo. Fuente: ALMANDOZ, 2004, p. 62.

Con todo, las transformaciones que experimentó la ciudad durante este periodo resultaron determinantes en los efectos que tendría el sismo de 1900. No es posible soslayar que este evento irrumpe en una Caracas que recientemente había atravesado un proceso de renovación arquitectónica y urbana, dirigido a borrar las viejas huellas de la devastación de 1812 y de las guerras. La Caracas de 1900 era una ciudad pequeña, horizontal, cuyas construcciones más altas tenían apenas dos pisos, y cuyos edificios más importantes eran obras nuevas o renovadas por la mano de los arquitectos e ingenieros más notables de la época.

Aunque esta imagen está fechada en los primeros años del siglo XX, el paisaje corresponde a las descripciones de la Caracas finisecular, hechas por los novelistas Manuel Díaz Rodríguez (1901) y Rufino Blanco Fombona (1904). Esto significa que la ciudad sacudida por el terremoto de 1900, tenía el mismo aspecto que contemplamos en la imagen. La silueta resultante de la renovación guzmancista permitía observar las mejoras que habían sido introducidas en la capital crespista, aunque no todas pudieran

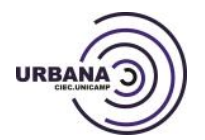

REVISTA ELETRONICA DO CENTRO INTERDISCIPLINAR DE ESTUDOS SOBRE A CIDADE . ISSN 1982-0569 v. 7, n. 10, jan /ago (2015). Dossiê História Urbana: a configuração de um campo conceitual 
ser percibidas desde la colina. Las tradicionales calles de piedras comenzaban a ser remplazadas por superficies de concreto, los espacios públicos se mantenían limpios. En cuanto a los servicios urbanos, aunque la iluminación por gas estaría en uso hasta comienzos del nuevo siglo, las luces eléctricas estuvieron más presentes a partir de mediados de los 90 gracias a la creación de la Electricidad de Caracas y la instalación de una nueva planta hidroeléctrica. Con respecto al transporte público las líneas de tranvías a caballos estuvieron trajinando hasta los años de 1900 y solo comenzarán a funcionar los tranvías eléctricos en 1908 (ALMANDOZ, 2006, pp. 177-179).

A nivel académico desde 1895 la arquitectura fue incorporada como programa de dos años a la recientemente creada Escuela de Ingeniería denotando la importancia de la labor de los arquitectos en la construcción de las obras. Profesionales como Luis Malaussena y Alejandro Chataing construyen nuevas "quintas" de la urbanización "El Paraíso". Desde mediados de los años 1889 se construye la "ciudad nueva", nombre original del suburbio. Zona residencial de caché que contaba con modernas redes de servicios de agua, cloacas, electricidad y trazado de jardinerías y plazas. El desarrollo urbanístico de El Paraíso fue acelerado, consecuencia del terremoto de 1900, que hizo que algunas familias burguesas decidieran construir, en aquellos terrenos, casas contra temblores.

Estas viviendas consistían en estructuras metálicas prefabricadas importadas de Inglaterra y Estados Unidos, que luego eran ensambladas, combinando la estructura de hierro con muros de concreto por los ingenieros Alberto Smith y Roberto García (Imagen 6). Hacia el noroeste la ciudad se expande en los suburbios llamados La Pastora y San José donde se localizan familias trabajadoras en casitas más modestas que las exóticas quintas de El Paraíso (ALMANDOZ, 2006, p. 177-183). Todos estos cambios espaciales y sociales se estaban dando en la Caracas de Crespo y Castro, e ilustran la imagen de la ciudad a finales del siglo XIX al momento en el que el sismo de San Narciso hace su entrada en escena.

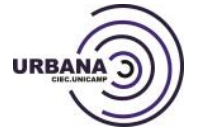




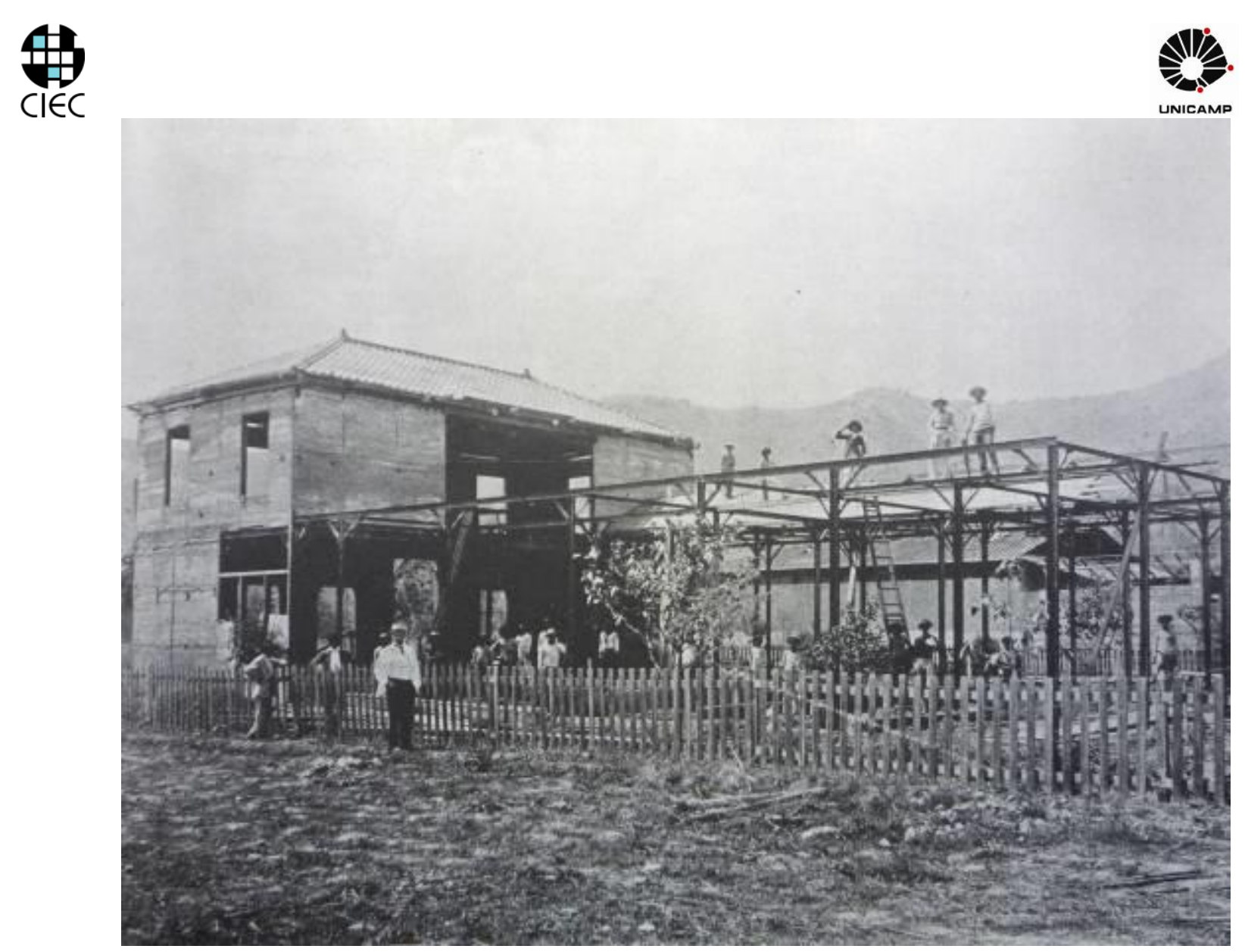

Imagen 6. Casa a prueba de temblores en El Paraíso (s.a.). El Cojo Ilustrado, 15 de mayo de 1901, N²26, 15, p. 333.

En la imagen podemos observar el proceso de construcción de una de las casas contra temblores, a cargo del ingeniero Alberto Smith, profesional avezado, de sólida trayectoria y excelente reputación, que supo aprovechar la espléndida oportunidad comercial que le brindaba el miedo inspirado por el terremoto de 1900. La fotografía resulta particularmente significativa porque muestra tanto la estructura metálica que se suponía dotaba a la casa de cierta resistencia sísmica, como el vaciado de los muros de concreto y la incorporación del techo metálico.

\section{El último terremoto del siglo XIX}

El terremoto ocurrido el día 29 de octubre de 1900 -día de San Narciso-, aproximadamente a las 4:42 de la mañana (hora local), sacudió todo el centro norte costero de Venezuela. El terremoto de San Narciso constituye un ejemplo perfecto de la complejidad intrínseca que reviste los eventos sísmicos: se trató del sismo superficial de mayor magnitud conocido en la historia sísmica del país, pero ocasionó relativamente pocos daños y menos víctimas en las poblaciones arquitectónicamente horizontales -y 
de baja densidad demográfica- de una Venezuela rural, cuyo perfil urbano estaba dominado por el adobe, la tapia y el bahareque (LEAL GUZMÁN, RODRÍGUEZ y AUDEMARD, 2014, pp. 89-91). Caracas y La Guaira, salieron mucho mejor libradas del sismo de 1900, por ejemplo, que de su antecesor, el terrible terremoto que las devastó el 26 de marzo de 1812, cuyo saldo fatal superó ampliamente los efectos del sismo de San Narciso. En comparación con aquel terremoto, referencia cercana y comprensible en las poblaciones aledañas a Caracas, el sismo de 1900 fue un fortísimo y aterrador remezón telúrico, pero del cual escaparon relativamente indemnes; e insistimos en el término relativamente, porque este terremoto dejó tras de sí la correspondiente estela de destrozos y un considerable malestar social.

En la coyuntura ocasionada por el terremoto de 1900, el significativo papel del Colegio de Ingenieros (CIV) como agente urbano se hizo manifiesto de inmediato. Una de las primeras medidas tomadas por el presidente Cipriano Castro fue recurrir a esta institución para encargarle no sólo el examen de los edificios caraqueños, sino también la tarea más complicada de elaborar las recomendaciones constructivas pertinentes ("Examen de la ciudad", La Linterna Mágica, Caracas: 3 de noviembre de 1900, p. 2). Esta medida fue muy aplaudida considerando que el Gobierno acudía al CIV con la firme intención de "oír la voz de la ciencia de las construcciones y proceder en consecuencia" ("Cuestiones actuales", La Religión, Caracas: 5 de noviembre de 1900, p. 2).

Dicha institución se posicionaba como un agente urbano sumamente significativo al jugar un papel decisivo tanto el peritaje de los daños producidos por el terremoto de 1900 como en las reflexiones que se suscitaron respecto a los sistemas constructivos apropiados a un país de terremotos y a la necesidad de contar con un código de construcción contra temblores (LEAL GUZMÁN y MASTRANGIOLI, 2014, pp. 577-580). Ante la convocatoria oficial, el CIV destacó tres comisiones técnicas para evaluar los daños producidos en los templos, los edificios públicos y las casas particulares de la ciudad de Caracas y, posteriormente, encargó a los profesionales Roberto García, Alejandro Chataing, Diego Morales y Ricardo Razetti, la redacción de un informe sobre los mejores modos de construir en un país sísmico, como Venezuela (LEAL GUZMÁN, RODRÍGUEZ y AUDEMARD, 2014, pp. 97-107).

Para valorar debidamente la participación del CIV, es menester recordar que en el año de 1900 no existían en el país instituciones específicamente encargadas de

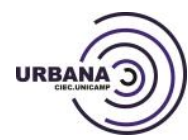

REVISTA ELETRONICA DO CENTRO INTERDISCIPLINAR DE ESTUDOS SOBRE A CIDADE . ISSN 1982-0569 v. 7, n. 10, jan /ago (2015). Dossiê História Urbana: a configuração de um campo conceitual 
estudiar y monitorear la actividad sísmica venezolana o de lidiar con las consecuencias de un terremoto destructor, aunque sí contábamos con entes vinculados a las decisiones sobre riesgos y amenazas sísmicas, por ejemplo, el Observatorio Cagigal existía desde el año 1889 y esa eficiente institución que fue el Ministerio de Obras Públicas se encontraba en funcionamiento desde el año 1874. Por otra parte, a finales del siglo XIX, las relaciones entre las instancias científicas -en este caso las instituciones que producían conocimiento sobre los sismos y las construcciones- y las instancias de poder político -las instituciones o las personas que tomaban las decisiones- no estaban claramente establecidas como una estrategia productiva para enfrentar las consecuencias de un terremoto. De hecho, este proceso de interacción entre actores científico-técnicos y Gobierno apenas comenzaría a gestarse hacia la década de 1940 y terminaría afianzándose a raíz del terremoto de El Tocuyo del 3 de agosto de 1950.

\section{EI terremoto en Caracas}

En Caracas viviendas, templos y edificios públicos acusaron los efectos destructores del terremoto: "(...) todas las casas resultaron averiadas (...) De las numerosas iglesias solamente la de Las Mercedes ha sufrido menos; todas las demás muestran graves daños y fueron cerradas (...) La mayoría de los edificios públicos (...) así todos los cuarteles han quedado inhabitables. Los grandes hoteles de uno o dos pisos están totalmente abandonados (...)" (AHRENSBURG, 1901, p. 57). El saldo destructor del terremoto, en lo que se refiere a las viviendas resultó, cuando menos, desalentador: "No hay, puede decirse, una casa en Caracas que no haya sufrido con el horrible sacudimiento. Techos hundidos, paredes rajadas, etc., etc. Los habitantes deben estar prevenidos" ("Lo de Hoy", El Conciliador, Caracas: 29 de octubre de 1900, p. 2).

Así pues, entre la fuerza de la sacudida principal, las réplicas y las lluvias variables que profundizaron el deterioro inicial-, el diario La Religión, publicaba el siguiente "resumen de los estragos hechos por el terremoto en Caracas (...) Casas caídas, 69. Casas en ruinas, 428. Casas que han perdido sus aleros, 174" ("Notas al susto", La Religión, Caracas: 7 de noviembre de 1900, p. 3). Aterrorizados por la secuencia de réplicas que siguió a la sacudida del 29 de octubre, la mayoría de los vecinos se negó a regresar a sus viviendas, más aún cuando casas aparentemente intactas escondían desperfectos en diversos grados que sólo se manifestaban tras un minucioso examen o tras recibir el impacto de una réplica o incluso de las torrenciales 
lluvias que se presentaron en aquellos días: "Hay que no fiarse, pues, de las ruinas disfrazadas de casas buenas y tener mucho ojo con las paredes desplomadas y con las que están partidas en sus bases" ("¿Y qué tal?", La Linterna Mágica, Caracas: 4 de noviembre de 1900 , p. 2). Considerando lo anterior, muchos caraqueños permanecieron al descampado, por espacio aproximado de mes y medio después de ocurrido el terremoto. Algunos establecieron precarias habitaciones en sus propios patios $y$ corrales. Por su parte, varias familias honorables se asilaron en las instalaciones del Nuevo Matadero de Caracas, edificio de muy reciente construcción que nada había sufrido con el remezón, en tanto que otras se establecieron en las estaciones de las Compañías de Ferrocarriles de La Guaira a Caracas y de Caracas a Valencia.

Para quienes no optaron por las opciones antes descritas, aún quedaban las plazas, los jardines públicos, los paseos... Cabe destacar que la permanencia de los caraqueños en estos espacios se vio favorecida, precisamente, por aquel afán modernizador de Guzmán Blanco y su interés en dotar a Caracas de plazas, paseos y alamedas que, al fin y al cabo, resultaron muy acogedores a los asustados vecinos. Entre estos espacios, herencia del gobierno guzmancista, destacaba un nuevo tipo de plaza, arbolada y dotada de mobiliario urbano "que se diferencia definitivamente de la plaza colonial austera y vacía" (HERNÁNDEZ DE LASALA, 1997, pp. 134-135). Siguiendo lo anterior, comprenderemos que estos espacios públicos conformaban una parte significativa del imaginario urbano de los caraqueños, lo que facilitó simbólicamente su toma y transformación en campamentos. A pesar del frío de noviembre y luego de las Iluvias, que no favorecían la permanencia a descampado, las plazas más grandes de la ciudad acogieron entonces a los temerosos vecinos, situación que se prolongó prácticamente hasta mediados del mes de diciembre.

La ingente afectación de los edificios públicos tuvo como primera consecuencia una mudanza generalizada de dichas instituciones como medida imprescindible para mantenerlas en funcionamiento. El terremoto también tuvo el efecto de evidenciar la necesidad de edificar nuevas sedes para las instituciones públicas en diversos puntos de la ciudad, contribuyendo así al ensanche de la población y a la revalorización del suelo ("Letra menuda", El Conciliador, Caracas: 6 de noviembre de 1900, p. 3). El sismo de 1900 es, de hecho, el primer terremoto de Caracas que inspira ideas de expansión urbana y que impulsa la adopción de nuevas tecnologías constructivas. Ninguno de los eventos sísmicos previos que afectaron a la ciudad tuvo consecuencias semejantes: por

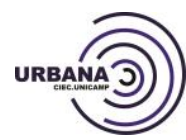

REVISTA ELETRONICA DO CENTRO INTERDISCIPLINAR DE ESTUDOS SOBRE A CIDADE . ISSN 1982-0569 v. 7, n. 10, jan /ago (2015). Dossiê História Urbana: a configuração de um campo conceitual 
el contrario los devastadores terremotos de 1641 y 1812 habían originado auténticos periodos de letargo urbano. En medio de las carencias económicas y técnicas que caracterizaron al siglo XVII venezolano, el sismo de San Bernabé implicó un duro proceso de recuperación que sólo pudo resolverse tres décadas más tarde.

En el caso de los eventos de 1812, el Cabildo tomó medidas para impedir la expansión de la ciudad, al prohibir la fabricación de casas fuera de los límites que tenía Caracas a principios del siglo XIX, situación que ha sido descrita como una clara expresión de antiurbanismo (ARELLANO MORENO, 1967, pp. 89-93). Por el contrario, en 1900, el contexto favorecía diversas opciones frente al sismo del 29 de octubre. Desde finales del siglo XIX y durante todo el siglo XX, los terremotos destructores han abierto espacios nuevos para la urbanización, la especulación inmobiliaria y también para las innovaciones constructivas. No podía ser de otra forma: el terremoto de 1900 había estado precedido por el proceso de modernización urbana impulsado por el gobierno de Guzmán Blanco, circunstancia que bien podríamos denominar como un "salto cultural", considerando que este proceso significó un cambio en la forma de pensar la ciudad.

El terremoto, entre otra cosas, tuvo el efecto inmediato de develar la dinámica de los agentes urbanos que existían en la ciudad, pues como afirmaba el diario La Religión: "(...) ante las ruinas de Caracas tenemos los siguientes actores: el Gobierno, los propietarios, los inquilinos, los ingenieros, los artesanos" ("Cuestiones actuales", La Religión, Caracas: 5 de noviembre de 1900, p. 2). Estos agentes urbanos de 1900 actuaron como intérpretes del sismo y de las lecciones dejadas por éste, reflexionando en el marco de referencia proporcionado por el proceso de modernización impulsado por Guzmán Blanco desde 1870. El criterio que prevaleció en el pensamiento de los observadores e intérpretes del terremoto de 1900 fue más urbano que exclusivamente ingenieril y arquitectónico. Al mismo tiempo que presentaban recomendaciones constructivas y discutían sobre los mejores modos de edificar en una ciudad y en un país sísmico, señalaban la necesidad de prestar atención a la relación e interacción existente entre los edificios; es decir, que no bastaba con que edificios aislados fuesen adecuadamente reparados o construidos, porque aquellos que no estuviesen sujetos a procedimientos edificatorios contra temblores, seguirían representando un riesgo para toda la ciudad.

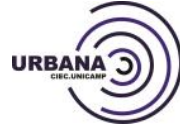

REVISTA ELETRONICA DO CENTRO INTERDISCIPLINAR DE ESTUDOS SOBRE A CIDADE . ISSN 1982-0569 v. 7, n. 10, jan /ago (2015). Dossiê História Urbana: a configuração de um campo conceitual 
Así mismo, el terremoto les llevó a identificar la configuración históricamente vulnerable de Caracas, cuya normativa urbana -incluso las Ordenanzas referidas a la arquitectura civil-, no incorporaba contenidos relacionados al riesgo sísmico. En este sentido, los agentes urbanos de la época comprendieron que la filosofía, objetivos y resultados de los reglamentos de policía, instrumento que determinaba alineación y altura de las edificaciones, e intentaba regular el ejercicio de los artesanos de la construcción, difería radicalmente de la esencia de un código de construcción contra temblores. Este último era un reglamento específicamente dirigido a reducir al mínimo los posibles daños estructurales y no estructurales ante terremotos de mediana intensidad, cuyos contenidos son definidos por actores técnicos, mientras que su observancia y cumplimiento queda en manos de las autoridades respectivas. De tal suerte, en los días posteriores al sismo, los miembros del CIV propusieron la elaboración y el estricto cumplimiento de un código de construcción que atendiese los fenómenos seísmicos a los que estaba expuesta la ciudad.

\section{Terremotos, evolución urbana y lecciones sísmicas}

El análisis sistemático de los sismos que ha sufrido una ciudad nos informa de cuál ha sido el impacto urbano de cada uno de estos eventos y de la relación histórica que entrelaza los efectos de un temblor con los efectos del siguiente. La observación de la relación sismicidad histórica-evolución urbana se dirige a partir de las siguientes interrogantes: ¿cómo se ha manifestado la amenaza sísmica en una ciudad determinada?, ¿cómo se distribuyeron los daños en cada ocasión?, ¿se repiten los sectores afectados y cuál es la razón?, ¿qué ha ocurrido con las edificaciones dañadas por los sismos?, ¿fueron reparadas o demolidas?, ¿se reconstruyeron en el emplazamiento original o fueron desplazadas?, ¿han ocurrido cambios urbanos y arquitectónicos significativos en las localidades más afectadas por el sismo o en la ciudad en general?, ¿estas transformaciones han disminuido o aumentado los grados de riesgo y vulnerabilidad?, ¿cuáles han sido las lecciones sísmicas que han dejado los terremotos?, ¿se han aprendido estas lecciones o permanecen ignoradas?

En este sentido, es de tenerse en cuenta que un terremoto destructor constituye un acontecimiento capaz de perturbar o transformar toda la estructura de la ciudad. A raíz de la ruina material provocada por un sismo se activan procesos de desplazamientos

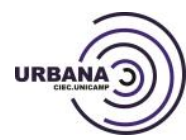

REVISTA ELETRONICA DO CENTRO INTERDISCIPLINAR DE ESTUDOS SOBRE A CIDADE . ISSN 1982-0569 v. 7, n. 10, jan /ago (2015). Dossiê História Urbana: a configuração de um campo conceitual 
de población, de rehabilitación y reconstrucción de edificaciones o de sectores, de urbanismo y de ocupación social del espacio, incluso de mudanza de la ciudad, cuyas consecuencias se dejan sentir durante los años posteriores al evento y que representan, por lo tanto, factores importantísimos en la reconfiguración de riesgos y vulnerabilidades. Los momentos posteriores a la irrupción de un terremoto constituyen el punto crítico en el que comienzan a producirse socialmente los próximos desastres y emergencias sísmicas. En tal circunstancia, el urbanismo se erige como herramienta de primer orden para extraer e interpretar las lecciones sísmicas y aplicarlas para fortalecer la ciudad contra futuros temblores.

Visibilizar la sismicidad histórica de Caracas en relación a su evolución urbana significa reflexionar sobre el crecimiento y expansión de la ciudad a partir, por ejemplo, de las devastadoras consecuencias de los terremotos de 1641 y 1812 . Cabe preguntarse si acaso Caracas no hubiese sido una ciudad más próspera y de mayor crecimiento de no haber mediado, en su devenir, estos dos sismos que arrasaron con los hitos urbanos y paralizaron su expansión durante décadas. Pensar Caracas a través de sus terremotos, implica revisar las lecciones del sismo de 1766, evento que evidenció las flaquezas de los edificios para que los caraqueños pudiesen corregirlas a tiempo; o incluso, retomar las reflexiones inspiradas por el terremoto de 1900, respecto a planificación urbana, microzonificación y sismorresistencia. Pensar a Caracas como ciudad telúrica significa también comprender que la amenaza sísmica es intrínseca a su sustrato urbano, y este reconocimiento puede marcar la diferencia en cuanto a la reducción del riesgo sísmico, porque una sociedad sólo produce estrategias de mitigación frente a las amenazas y a los riesgos que son percibidos como tales, abordando entonces la producción y la planificación de ciudades desde un enfoque auténticamente sustentable.

\section{Referencias bibliográficas:}

Fuentes primarias inéditas:

Archivo General de la Nación (AGN), Sección Traslados, Obispo Fray Mauro de Tovar, Tomo I, f. 299.

\section{Prensa:}

La Linterna Mágica (1900).

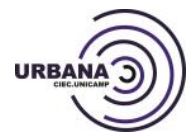


La Religión (1900).

El Conciliador (1900).

El Cojo Ilustrado (1900-1901).

\section{Libros y artículos:}

ADUAR. Diccionario de geografía urbana, urbanismo y ordenación del territorio. Barcelona: Ariel, 2000.

AHRENSBURG, $\mathrm{H}$. Erbeben in Caracas. Abdruck aus den Mitteilungen der Geographischen Gesellschaft (für Thuringen) zu Jena. Band XIX., p. 56-58, januar, 1901 (Trad. Christl Palme).

ALMANDOZ, A. El primer estrato de modernidad: el Guzmanato y la Bella época. En: EXXON MOBIL, Santiago de León de Caracas. 1567-2030. Caracas: Editorial Arte, 2004, p. $12-64$

ALMANDOZ, A. Urbanismo europeo en Caracas. 1870-1940. Caracas: Fundación para la Cultura Urbana, 2006.

ALTEZ, R. El desastre de 1812 en Venezuela. Sismos, vulnerabilidades y una patria no tan boba. Caracas: Universidad Católica Andrés Bello, Fundación Polar, 2006.

ARCILA FARÍAS, E. Historia de la ingeniería en Venezuela. Caracas, Colegio de Ingenieros de Venezuela, 1961, 2 tomos.

ARELLANO MORENO, A. Caracas, su evolución y su régimen legal. Caracas: Ediciones del Cuatricententenario de Caracas, 1967.

BRAVO, C. Tres visiones de Caracas. La ciudad decimonónica a través de sus testimonios pictóricos y gráficos En: Argos, v. 25, n. 48, p. 44-69, junio, 2008.

BRITO FIGUEROA, F. La estructura social y demográfica de Venezuela Colonial. Caracas: Ediciones Historia, 1961.

BOLÍVAR, S. Manifiesto de Cartagena. Memoria dirigida a los ciudadanos de la Nueva Granada por un caraqueño). En: PEREIRA, G. Simón Bolívar, escritos anticolonialistas. Caracas: Ediciones Correo del Orinoco, 2013, p. 30-49.

CARABALLO PERICI, C. Los últimos días de aquella de los techos rojos, o los "planes" antes del "plan". En: INSTITUTO DE URBANISMO, El Plan Rotival: la Caracas que no fue: 1939-1989, Caracas: Ediciones Instituto de Urbanismo, Facultad de Arquitectura y Urbanismo, Universidad Central de Venezuela, 1991, p. 49-72.

CENTENO GRAÜ, M. Estudios sismológicos. 2. ed. Caracas: Academia Nacional de Ciencias Físicas, Matemáticas y Naturales, Talleres Tipo-litográficos de la Dirección de Cartografía Nacional,1969.

CHOY, J., PALME, C., GUADA, C., MORANDI, M. y KLARICA, S. Macroseismic interpretation of the 1812 earthquakes in Venezuela using intensity uncertainties and a

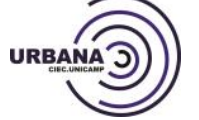

REVISTA ELETRONICA DO CENTRO INTERDISCIPLINAR DE ESTUDOS SOBRE A CIDADE . ISSN 1982-0569 v. 7, n. 10, jan /ago (2015). Dossiê História Urbana: a configuração de um campo conceitual 
priori fault-strike information In: Bulletin of the Seismological Society of America, v. 100 , n. 1, p. 241-255, february, 2010.

CUNILL GRAÜ, P. Geohistoria de la Caracas insurgente. 1810-1812. Caracas:

Fundación Centro Nacional de Historia, 2012.

DE SOLA RICARDO, I. Contribución al estudio de los planos de Caracas. 1567-1967. Caracas: Ediciones del Cuatricentenario de Caracas, 1967.

DÍAZ, J. D. Recuerdos sobre la rebelión de Caracas. Caracas: Fundación Biblioteca Ayacucho, 2012.

DORTA, E. M. Materiales para la historia de la cultura en Venezuela (1523-1828). Documentos del Archivo General de Indias de Sevilla. Caracas: Fundación John Boulton, 1967.

DUARTE, C. Juan Pedro López: maestro de pintor, escultor y dorador, 1724-1787. Caracas: Galería de Arte Nacional, 1996.

GARCÍA CHUECOS, H. Estudios de Historia Colonial Venezolana. Caracas: Tipografía Americana, 1938, 2 tomos.

GASPARINI, G. \& POSANI, J. P. Caracas a través de su arquitectura. Caracas: Editorial Armitano, 1998.

GUIDOBONI, E. and FERRARI, G. Historical variables of seismic effects: economics levels, demographic scales and building techniques. In: Annali di Geofisica, v. 43, n. 4. p. 687-705, august, 2000.

HERNÁNDEZ DE LASALA, S. Venezuela entre dos siglos. La arquitectura de 1870 a 1930. Caracas: Armitano Editores, 1997.

IRIBARREN, M. Oficio de alarife. Caracas: Archivo General de la Nación, Centro Nacional de Historia, 2010.

LEAL GUZMÁN, A.; MASTRANGIOLI, G. Imaginario social de la sismorresistencia en la Venezuela del siglo XIX En: TRIENAL DE INVESTIGACIÓN FAU, 7, 2014, Caracas. Memorias de la Trienal de Investigación FAU 2014. Caracas, 2014, p. 571-582.

LEAL GUZMÁN, A.; AUDEMARD, F.; RODRÍGUEZ, J. A. Terremotos y lecciones urbanas. Caso del sismo de San Narciso del 29 de octubre de 1900 en la ciudad de Caracas. En: TRIENAL DE INVESTIGACIÓN FAU, 7, 2014, Caracas. Memorias de la Trienal de Investigación FAU 2014. Caracas, 2014, p. 304-315.

LEAL GUZMÁN, A.; RODRÍGUEZ J. A.; AUDEMARD, F. A prueba de temblores. Reflexiones sobre construcciones y sismorresistencia en la Venezuela de 1900. Caso del sismo de San Narciso del 29 de octubre de 1900. Boletín de la Academia Nacional de la Ingeniería y el Hábitat, v. 1, n. 26, p. 89-134, mayo, 2014.

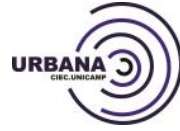

REVISTA ELETRONICA DO CENTRO INTERDISCIPLINAR DE ESTUDOS SOBRE A CIDADE . ISSN 1982-0569 v. 7, n. 10, jan /ago (2015). Dossiê História Urbana: a configuração de um campo conceitual 
MOBIL DE VENEZUELA. Caracas cuatricentenaria: su crecimiento a través de 14 planos. Caracas: Departamento de Relaciones Públicas de Mobil de Venezuela, 1966.

MUSSET, A. Ciudades nómadas del Nuevo Mundo. México: Fondo de Cultura Económica, 2011.

OTADUY, E. Las Iglesias de la antigua Caracas. Caracas: Imprenta Municipal, 1974.

PINO ITURRIETA, E.; CALZADILLA, P. E. La Mirada del otro: viajeros extranjeros en la Venezuela del siglo XIX. Caracas: Fundación Bigott, 1993.

SALAZAR, R. Los arrabales. Aproximación a la periferia de Caracas a fines del siglo XVIII. En: Argos, v. 25, n. 49, p. 73-84, diciembre, 2008.

WOLF, E. Europa y la gente sin historia. Buenos Aires: Fondo de Cultura Económica, 2000.

YUJNOVSKY, O. La estructura interna de la ciudad. El caso latinoamericano. Buenos Aires: Ediciones S.I.A.P., 1971.

ZAWISZA, L. Arquitectura y obras públicas en Venezuela. Siglo XIX. Caracas: Ediciones de la Presidencia de la República, 1988, 3 vols.

ZAWISZA, L. La crítica de la arquitectura en Venezuela durante el siglo XIX. Caracas: Consejo Nacional de la Cultura, 1998. 